\title{
A Fundamental Consideration on NOx Adsorber Technology for DI Diesel Application
}

Howard L. Fang, Shyan C. Huang and Robert C. Yu

Cummins Inc.

C. Z. Wan

Engelhard Corporation

Ken Howden

Department of Energy, Office of Advanced Automotive Technologies

Powertrain \& Fluid Systems

Conference \& Exhibition 
All rights reserved. No part of this publication may be reproduced, stored in a retrieval system, or transmitted, in any form or by any means, electronic, mechanical, photocopying, recording, or otherwise, without the prior written permission of SAE.

For permission and licensing requests contact:

SAE Permissions
400 Commonwealth Drive
Warrendale, PA 15096-0001-USA
Email: permissions @ sae.org
Fax: $724-772-4028$
Tel: $\quad 724-772-4891$

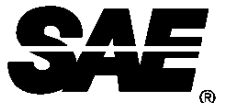

Global Mobility Database ${ }^{\ominus}$

All SAE papers, standards, and selected books are abstracted and indexed in the Global Mobility Database.

For multiple print copies contact:

SAE Customer Service

Tel: $\quad$ 877-606-7323 (inside USA and Canada)

Tel: $\quad$ 724-776-4970 (outside USA)

Fax: $\quad$ 724-776-1615

Email: CustomerService@sae.org

\section{ISSN 0148-7191}

\section{Copyright $\odot 2002$ SAE International}

Positions and opinions advanced in this paper are those of the author(s) and not necessarily those of SAE. The author is solely responsible for the content of the paper. A process is available by which discussions will be printed with the paper if it is published in SAE Transactions.

Persons wishing to submit papers to be considered for presentation or publication by SAE should send the manuscript or a $\mathbf{3 0 0}$ word abstract of a proposed manuscript to: Secretary, Engineering Meetings Board, SAE.

\section{Printed in USA}




\title{
A Fundamental Consideration on NOx Adsorber Technology for DI Diesel Application
}

\author{
Howard L. Fang, Shyan C. Huang and Robert C. Yu \\ Cummins Inc.
}

C. Z. Wan

Engelhard Corporation

Ken Howden

Department of Energy, Office of Advanced Automotive Technologies

Copyright @ 2002 SAE International

\begin{abstract}
Diesel engines are far more efficient than gasoline engines of comparable size, and emit less greenhouse gases that have been implicated in global warming. In 2000, the US EPA proposed very stringent emissions standards to be introduced in 2007 along with low sulfur (<15 ppm) diesel fuel. The California Air Resource Board (CARB) has also established the principle that future diesel fueled vehicles should meet the same low emissions standards as gasoline fueled vehicles and the EPA followed suit with its Tier II emissions regulation. Achieving such low emissions cannot be done through engine development and fuel reformulation alone, and requires application of NOx and particulate matter (PM) aftertreatment control devices. There is a widespread consensus that NOx adsorbers and particulate filter are required in order for diesel engines to meet the 2007 emissions regulations for NOx and PM.
\end{abstract}

In this paper, the key exhaust characteristics from an advanced diesel engine are reviewed. Development of the NOx adsorber technology is discussed. Spectroscopic techniques are applied to understand the underlying chemical reactions over the catalyst surface during NOx trapping and regeneration periods. In-situ surface probes are useful in providing not only thermodynamic and kinetics information required for model development but also a fundamental understanding of storage capacity and degradation mechanisms. The distribution of various nitration/sulfation species is related to surface basicity. Surface displacement reactions of carbonates also play roles in affecting the trapping capability of NOx adsorbers. When ultralow-S fuel is used as a reductant during the regeneration, sulfur induced performance degradation is still observed in an aged catalyst. Other possible sources related to catalyst deactivation include incomplete reduction of surface nitration, coke formation derived from incomplete hydrocarbon burning, and lubricant formulations. Sulfur management and the direction of future work for the successful implementation of such integrated engine and aftertreatment technology are discussed.

\section{INTRODUCTION}

Considerable efforts have been spent through a partnership including resources of government, industry, and institute of higher learning to significantly reduce NOx and PM emissions while maintaining the superior advantage in fuel economy of diesel engines. Research on plasma-assisted catalytic reduction of NOx has been reviewed in a number of articles (1-3). The potential of lean NOx technology for diesel emission control has also been investigated (4-8). PM reduction has been demonstrated with a particulate filter and regeneration of the filter has been a subject of many studies (9-18). NOx adsorber technology to control NOx emissions becomes increasingly attractive for many engine manufactures (16-17). Improvements for NOx adsorber technology have been focused on the development of catalysts with more efficient NOx conversion and higher capacity for NOx storage over a wide exhaust gas temperature range and on a fundamental understanding of the deactivation mechanisms of the catalyst. Another important development area has been the hydrocarbon utilization or means to reduce the required fuel penalty. The effectiveness of various reductants (18) and the development of injection systems to provide an optimized reductant (19) were both reported on. There was an effort to develop the optimum time and fuel quantity for the regeneration event (20) when 
regeneration was required. Nevertheless, the most critical step though for NOx adsorber technology is the development of a more sulfur tolerant catalyst, or a sulfur management scheme, even if $15 \mathrm{ppm}$ [S] fuel is available. In addition, selective catalytic reduction (SCR) using urea has grown in economic and technologic importance. Different aspects using SCR for both stationary and mobile applications have also been reviewed in the literature (21-23).

NOx adsorber technology relies on a storagereduction approach that involves removal of NOx from the exhaust under lean conditions by adsorption, followed by periodic regeneration of the adsorbent along with reduction of the released NOx under rich conditions. This alleviates the need for maintaining a given $\mathrm{C}_{1} / \mathrm{NOx}$ ratio under transient and fluctuating exhaust NOx levels, as in the case of a transitional lean NOx catalyst. The key advantages of NOx adsorber technology include its high efficiency of NOx conversion (> $85 \%$ ) and its wide temperature range of operation. Another benefit is the use of on board diesel fuel as reductant, which exhibits easier enforcement/anti-tampering control and eliminates additional infrastructure such as the case with ureaSCR.

The adsorption of a NOx adsorber catalyst entails reaction of an acidic gas $\left(\mathrm{NO}_{2}\right)$ with a basic adsorbent (oxides or carbonates of alkali and alkaline earth elements, e.g. $\mathrm{BaO}$ and $\mathrm{BaCO}_{3}$ ) to form nitrate or nitroso-species, both on the catalyst surface. Since $\mathrm{NO}$ is known to show slower reactivity with metal oxides than $\mathrm{NO}_{2}$ and engine-out $\mathrm{NOx}$ primarily consists of NO (90\%), it must first be oxidized to $\mathrm{NO}_{2}$ over an oxidation catalyst (e.g. Pt based). When the effective storage capacity of the adsorber is below the desirable level, reductant (e.g. diesel fuel) is injected to establish a rich environment. Under this condition, the trapped $\mathrm{NOx}$ is reduced to $\mathrm{N}_{2}$ following a conventional three-way catalytic conversion principle. The operational temperature range of the NOx adsorber catalyst is governed by the low and high limits. The low limit is controlled by the light-off temperature required for the catalyst to oxidize NO into $\mathrm{NO}_{2}$ and the upper limit is determined by the temperature of thermodynamic stability of the trapped nitrogen oxide species (e.g. $\left.\mathrm{Ba}\left(\mathrm{NO}_{3}\right)_{2}\right)$. NOx adsorbers are generally stable to the hydrothermal conditions encountered in diesel exhaust. However, the adsorbent function (e.g. $\mathrm{BaO}$ around Pt sites) is extremely susceptible to deactivation from sulfur oxides in the exhaust by the formation of sulfated species [22] that hinder adsorption sites intended for $\mathrm{NO}_{2}$ storage [23]. Furthermore, the rich regeneration pulses not sufficient either in reactivity or in temperature to effectively release the SOx from the adsorber result in a rapid deactivation (from $100 \%$ to $20 \% \mathrm{NO}_{x}$ conversion) as seen when a NOx adsorber aged with a diesel fuel containing current sulfur levels $(0.05 \% \mathrm{~S})$.

\section{EMISSION REGULATION/CYCLE DEFINITION}

Based on EPA's Tier 2 emission standards that will be phased-in between 2004 and 2009, vehicles are classified based on gross vehicle weight rating (GVWR), and their applications. Passenger cars and light-duty trucks with GVWR less than $8500 \mathrm{lbm}$ are tested on chassis dynamometers using the FTP-75 cycle and Supplemental Federal Test Procedure (SFTP). The engines for heavy-duty vehicles with GVWR above $8500 \mathrm{lbm}$ are tested on engine dynamometers using the US Heavy Duty (US-HD) cycle and Supplemental Emission Test (SET). Medium-duty passenger vehicles (MDPV) and heavyduty diesel vehicles (HDDV) for GVWR up to 10,000 $\mathrm{lbm}$ and $14000 \mathrm{lbm}$, respectively, can be optionally tested using either light-duty standards or heavy-duty standards.

FTP-75 cycle specifies the vehicle speed over time, and emission standards are in $\mathrm{g} / \mathrm{mile}$. Three phases are included in this cycle: $0-505$ s cold transient, 506$1372 \mathrm{~s}$ cold stabilized, and $0-505 \mathrm{~s}$ hot transient. The hot transient phase is a repeat test of the cold transient phase, but with a 10 min soak period following the cold stabilized phase. Emissions from cold and hot start tests are combined using the weighting factors of 0.43 and 0.57 , respectively, with an assumption that the stabilized cold phase will have the same emissions as the hot start. Following Tier 2 standards, vehicle manufactures will have a choice to certify a specific vehicle to any of the 8 bins of different stringency. However, the entire vehicle fleet sold by each manufacturer will have to meet the average NOx standard of $0.07 \mathrm{~g} / \mathrm{mile}$.

US-HD cycle specifies the normalized engine speed and torque history with respect to the full-throttle torque curve, and the emission standards are in $\mathrm{g} / \mathrm{bhp}$-hr. There is a 20 min cold start transient cycle, followed by a repeat 20 min hot start transient cycle after a 20 min soak period. Unlike the FTP-75 cycle, the cold start emission has a much lower weighting factor, $1 / 7$ vs. $6 / 7$, for the hot start cycle. The NOx emission standard, $0.2 \mathrm{~g} / \mathrm{bhp}$-hr will be phased in between 2007 and 2010. Additionally, SET emission test using Euro III cycle will be required to meet the same FTP standard, and Not-to-Exceed (NTE) to meet 1.5 times the FTP standards.

\section{EXHAUST CHARACTERISITICS}

Under FTP-75 and US-HD cycles, engines will undergo very different speed and load history, as well as the exhaust characteristics. The engine calibration, such as the use of EGR, can also influence its exhaust characteristics. An advanced prototype Cummins 5.9L ISB engine equipped with cooled EGR was used to evaluate performance of various NOx adsorbers. 
Figure 1 shows one typical example of the engine-out NOx contribution vs. engine turbo-out temperature. Based on the thermal management for the aftertreatment system, the catalyst inlet temperature is lower than the turbo-out temperature by $20-50^{\circ} \mathrm{C}$. For FTP-75 cycle, about $20 \%$ of NOx will be emitted below $200^{\circ} \mathrm{C}$ during the cold-start vs. $7.5 \%$ during the hot-start. Since cold-start represents a significant portion of the overall light-duty emissions, it is essential to improve the low-temperature performance of the NOx catalyst, particularly for temperatures below $200^{\circ} \mathrm{C}$. For US-HD cycle, the majority of NOx is emitted when the engine turbo-out temperature is above $200^{\circ} \mathrm{C}$.

The plot of engine-out NOx contribution vs. catalyst space velocity is also shown in Figure 1, for catalyst volume of two times the engine displacement. For FTP-75 cycle, the majority of NOx is emitted when the space velocity is below $30 \mathrm{k} / \mathrm{hr}$. For US-HD cycle, a significant portion of $\mathrm{NOx}$ is emitted when the space velocity is $60-70 \mathrm{k} / \mathrm{hr}$. Higher space velocity generally represents higher NOx loading for the catalyst. All factors including temperature, space velocity and NOx loading need to be considered for the catalyst sizing in order to minimize the regeneration frequency and the associated fuel penalty.

Concentrations of $\mathrm{O}_{2}$ and $\mathrm{H}_{2} \mathrm{O}$ in engine exhaust are directly related to the engine $A / F$ ratio, which in turn is influenced by EGR configuration. Since NOx adsorber regeneration requires an $\mathrm{O}_{2}$-starving environment, the fuel injection penalty can be related to the $\mathrm{O}_{2}$ flow rate, which is determined by the exhaust flow rate and the $\mathrm{O}_{2}$ concentration. Figure 2 shows the engine-out $\mathrm{O}_{2}$ flow rates depicted for FTP75 and US-HD cycles. It is expected that the $\mathrm{H}_{2} \mathrm{O}$ content in exhaust may play a major role on the performance of the NOx adsorber because most base metal oxides of adsorber materials undergo rapid hydrolysis with $\mathrm{H}_{2} \mathrm{O}$. Dispersion of the precious metal and sorbate ingredients shows strong dependence on the physical state of the supporting material. Figure 2 also shows the engine-out $\mathrm{H}_{2} \mathrm{O}$ concentration based on complete combustion and dry ambient air. As indicated by Figure 2, the maximum $\mathrm{H}_{2} \mathrm{O}$ concentration is found to be less than $10 \%$, at low A/F conditions. The average $\mathrm{H}_{2} \mathrm{O}$ concentration over the emission cycles is between $4 \%-5 \%$.

\section{ANALYTICAL AND EXPERIMENTAL METHODS}

DRIFTS (diffused reflectance FTIR) (24-27) and Raman spectroscopy $(27,28)$ were used to characterize surface adsorbed species. Both are vibrational techniques permitting a sample depth profiling from several to hundred nanometers. A sketch of experimental setups for both techniques is depicted in Figure 3. During the nitration process, various nitrates and nitrites, including species in different chelation configurations such as uni- or bidentate geometry can be identified in the spectra. During the sulfation process, various oxy-sulfur species including sulfites, sulfates, bisulfates and pyrosulfates can be identified and discriminated (2934). The sensitivity of spectroscopic techniques provides information not only for the vibrational frequencies but also for rotational contours associated with the specific vibrational modes. Surface physisorbed, vapor-like $\mathrm{NO}_{2}$ (with the P/R branches at $1596 / 1626 \mathrm{~cm}^{-1}$ ) and $\mathrm{SO}_{2}$ (with Q-branch at $1358 \mathrm{~cm}^{-1}$ ) can be seen in the spectra, particularly for samples operated at relatively low temperatures, $<300^{\circ} \mathrm{C}$.

In-situ DRIFTS measurements were conducted by a SpectraTech unit attached to a standard FTIR spectrometer. Within the unit, the incident IR was directed onto the sample through the front portion of a parabolic mirror and the diffused signal was collected through the back portion of the mirror. The powdered sample was sealed under a $\mathrm{ZnSe}$ dome and heated by an electric heater mounted underneath the sample cup. The reaction gas flowed through the dome with the desired rates. Surface adsorbed species accumulated on the top twodimensional overlayer were investigated by exposing catalytic powder to the reaction gas $\left(0.1 \% \mathrm{NO}_{2}\right.$ or $0.98 \% \mathrm{SO}_{2}$ in $\mathrm{N}_{2}$ or air) under the desired conditions of temperatures and flow rates. The spectrum of $\mathrm{KBr}$ powder at each specific temperature was used as the background for other spectra collected at the same temperature. All spectra were collected in singlebeam mode and ratioed to the single-beam spectrum of $\mathrm{KBr}$ background in order to generate the spectra in absorbance unit.

For off-line measurements in DRIFTS, samples were loaded in a packed-bed reactor and exposed to the reaction gas at the desired temperatures. The flow rate in packed-bed reactor was adjusted much larger than the one used for in-situ measurements and all sample particles were exposed to the reaction gas. This was in contrast to in-situ measurements where only the top surface overlayer of a sample was in contact with the reaction gas.

Raman can be a powerful tool to identify surface adsorbed species as long as these surface-mediated species are not significantly fluorescent. Raman data were collected using a Renishaw Ramanscope equipped with two holographic Notch filters, an electrically cooled CCD camera and an $\mathrm{Ar}^{+}$laser. The excitation source was focused onto the sample through a microscope. Laser power was maintained at a low level, $<5 \mathrm{~mW}$, in order to avoid any thermal heating.

Both DRIFTS and Raman are generally considered as qualitative techniques. When a well-characterized 
internal reference is used, quantitative information may be obtainable. Time sequence of surface buildups of a specific species may also carry some kinetics information. Thus, spectral measurements of a specific absorption band on the catalyst at various times within the stream may reveal a catalyst deactivation mechanism.

Model powder samples for this study, such as $\mathrm{BaO}$, $\mathrm{Al}_{2} \mathrm{O}_{3}, \mathrm{CaO}$ were obtained from Alfa without further treatment. Fully formulated NOx adsorber catalysts, SOx trap catalyst and catalyzed soot filters for engine tests were obtained from Engelhard.

\section{NOX ADSORBER FUNDAMENTAL-NOX STORAGE AND REGENERATION}

For $\mathrm{BaO}-$ based catalysts, $\mathrm{BaO}$ interacts rapidly with moisture and $\mathrm{CO}_{2}$ in the exhaust to form a mixture of $\mathrm{BaCO}_{3}$ and $\mathrm{Ba}(\mathrm{OH})_{2}$. It is found that $\mathrm{NO}_{x}$ conversion increases with increasing $\mathrm{O}_{2}$ concentration but decreases with increasing $\mathrm{CO}_{2}$ concentration. It is a general understanding $(35,36)$ that the trapping mechanisms of NOx adsorbers may involve several routes:

\section{(1) Oxidation of $\mathrm{NO}$}

$$
\mathrm{NO}+1 / 2 \mathrm{O}_{2} \rightarrow \mathrm{NO}_{2},
$$

(2) Disproportionation of $\mathrm{NO}_{2}$

$$
\mathrm{BaO}+3 \mathrm{NO}_{2} \rightarrow \mathrm{Ba}\left(\mathrm{NO}_{3}\right)_{2}+\mathrm{NO},
$$

(3) Displacement reactions of carbonates

$$
\mathrm{BaCO}_{3}+2 \mathrm{NO}_{2}+[\mathrm{O}] \rightarrow \mathrm{Ba}\left(\mathrm{NO}_{3}\right)_{2}+\mathrm{CO}_{2}
$$

(4) Hydrolysis of $\mathrm{BaO}$

$$
\begin{aligned}
& \mathrm{BaO}+\mathrm{H}_{2} \mathrm{O} \rightarrow \mathrm{Ba}(\mathrm{OH})_{2} \text { and } \\
& \mathrm{Ba}(\mathrm{OH})_{2}+\mathrm{CO}_{2} \rightarrow \mathrm{BaCO}_{3}+\mathrm{H}_{2} \mathrm{O} \text {, and }
\end{aligned}
$$

(5) Insertion reactions involving surface hydroxyl groups, such as $>-\mathrm{OH}+\mathrm{NO}_{2} \rightarrow>-\mathrm{ONO}_{2} \mathrm{H}$.

The burst of NOx at the beginning of each rich regeneration cycle suggests that the decomposition of metal nitrates may be the first step in the reduction mechanism. Upon reacting with hydrocarbons or other appropriate reductants during the regeneration, $\mathrm{Ba}\left(\mathrm{NO}_{3}\right)_{2}$ appears to first decompose to release $\mathrm{NOx}$ which will then be reduced to $\mathrm{N}_{2}$. Such NOx release can be depicted by a desorption process:

$2 \mathrm{CO}+\mathrm{O}_{2} \rightarrow 2 \mathrm{CO}_{2}+$ heat

$\mathrm{Ba}\left(\mathrm{NO}_{3}\right)_{2}+$ heat $\rightarrow \mathrm{BaO}+2 \mathrm{NO}_{2}+1 / 2 \mathrm{O}_{2}$, and
$2 \mathrm{NO}_{2}+$ heat $\rightarrow 2 \mathrm{NO}+\mathrm{O}_{2}$.

It is evident that this desorption process is sensitive to sample temperature. The release NOx will be reduced to $\mathrm{N}_{2}$ over precious metal (e.g. Pt) sites with additional available reductants. It was found that base metal oxides (BMOs), physically separated from Pt component, do not exhibit high trapping capacity for NOx and require more reductants during regeneration. Thus, an intimate contact of $\mathrm{Pt}$ and BMOs is apparently essential in determining the overall efficiency in NOx conversion. Insufficient reductant often leads to high NO release. Trapped NOx quantity also appears to affect the NOx reduction. It was determined that loosely trapped nitrated species tend to easily release as NO during regeneration. The reduction reaction also seems to depend on the type of reductants and the reduction temperature, especially for low temperature operations (e.g. $<250^{\circ} \mathrm{C}$ ). It appears that it is advantageous to keep the NOx adsorber near $100 \%$ trapping efficiency during the operation. This tends to minimize the NO release during regeneration. A development of adequate regeneration strategy consisting of optimization of lean NOx trapping time, regeneration time, lean/rich ratio and space velocity, is critical to a successful application of NOx adsorber technology.

\section{LOW TEMPERATURE PERFORMANCE IMPROVEMENT}

As characterized in Figure 1, the NOx adsorber catalyst located in the exhaust stream of our test engine spent most of the time during the FTP75 test cycle in the temperature range between $200^{\circ} \mathrm{C}$ and $250^{\circ} \mathrm{C}$. When diesel fuel is used as the reductant to regenerate the adsorber, the light-off temperature may not occur at or below $200^{\circ} \mathrm{C}$ due to limited oxidation of the fuel at low temperatures. One way to increase the activity is to transform the diesel fuel into light hydrocarbon constituents $\left(\mathrm{C}_{3}-\mathrm{C}_{8}\right)$. Table I summarizes the NOx trapping capacity of a $\mathrm{NOx}$ adsorber regenerated at $250^{\circ} \mathrm{C}$ using various light hydrocarbons as reductants in a laboratory experiment. As shown in Table I, the light hydrocarbon components (except propylene, more or less equivalent to diesel) are worse reductants than the diesel fuel for low temperature regeneration of a NOx adsorber.

Another way to improve the low temperature performance of NOx adsorbers is through a reforming process by converting the diesel fuel into $\mathrm{CO}$ and $\mathrm{H}_{2}$ since $\mathrm{CO}$ and $\mathrm{H}_{2}$ are generally more effective reductants than the hydrocarbons. Cyclic lean-rich experiments were conducted in the laboratory to confirm this hypothesis. A lean gas mixture containing $\mathrm{NO}, \mathrm{O}_{2}, \mathrm{CO}_{2}$ and water was passed through a NOx adsorber catalyst for two minutes and then the mixture was switched to a rich 
exhaust containing $\mathrm{CO}_{2}$, water and various $\mathrm{CO}$ and $\mathrm{H}_{2}$ mixtures for ten seconds at a constant catalyst inlet temperature. The total quantity of the reductant introduced during the ten seconds regeneration period was equivalent to three times the stoichiometric flux of the NOx during the lean exposure. The lean-rich switch was repeated more than 15 cycles. The cycle average of the NOx conversion was calculated based on the total NOx breakthrough and the total NOx flux during each measurement. Table II summarizes the experimental results. The syngas was found to be much more active than the diesel. In fact, all syngas samples with various $\mathrm{CO}$ and $\mathrm{H}_{2}$ contents can sufficiently lower the catalyst light off temperatures of the NOx adsorber below $180^{\circ} \mathrm{C}$. It clearly indicates that reforming of diesel fuel to syngas as reductant during the regeneration is an effective way to enhance the low temperature performance of a NOx adsorber catalyst.

Table I NOx trapping capacity of NOx adsorber at $250^{\circ} \mathrm{C}$

\begin{tabular}{|l|c|}
\hline Reductant & $\mathrm{NOx}$ Capacity at $250^{\circ} \mathrm{C}$ \\
\hline ultra-low [S] diesel & $0.54 \mathrm{gNO}_{2} / \mathrm{l}$ (base case) \\
\hline propylene & $1.04 \times$ base \\
\hline isobutane & 0 \\
\hline o-xylene & $0.7 \times$ base \\
\hline n-octane & $0.074 \times$ base \\
\hline iso-octane & 0 \\
\hline
\end{tabular}

Table II Cycle NOx Conversions of NOx adsorber with various reductants

\begin{tabular}{|l|l|l|l|l|}
\hline \multirow{2}{*}{ Reductant } & \multicolumn{5}{|c|}{$\begin{array}{c}\text { Cycle NOx Conversion \% } \\
\text { (120s Lean / 10s Rich) }\end{array}$} \\
\cline { 2 - 5 } & $250^{\circ} \mathrm{C}$ & $225^{\circ} \mathrm{C}$ & $200^{\circ} \mathrm{C}$ & $180^{\circ} \mathrm{C}$ \\
\hline $\begin{array}{l}\text { ultra-low [S] } \\
\text { diesel }\end{array}$ & 92 & 81 & 58 & 5 \\
\hline $\mathrm{CO}$ & 100 & 100 & 93 & 81 \\
\hline $\mathrm{CO} / \mathrm{H}_{2}=3$ & 100 & 100 & 98 & 85 \\
\hline $\mathrm{CO} / \mathrm{H}_{2}=1$ & 100 & 100 & 100 & 95 \\
\hline
\end{tabular}

\begin{tabular}{|l|l|l|l|l|}
\hline $\mathrm{H}_{2} / \mathrm{CO}=3$ & 100 & 100 & 100 & 95 \\
\hline $\mathrm{H}_{2}$ & 100 & 100 & 100 & 95 \\
\hline
\end{tabular}

\section{SPECTROSCOPIC CHARACTERIZATION OF MODEL BULK METAL OXIDES}

Surface probe of adsorbing species using spectroscopic techniques is a useful tool to understand the underlying chemistry of the adsorption and the aging mechanism. Temperature and temporal probes of surface species provide not only the kinetics information governing the storage efficiency but also the early indication of catalyst fouling. A database for nitration/sulfation as well as de-nitration/de-sulfation of model metal oxides such as $\mathrm{CaO}, \mathrm{BaO}$ and $\mathrm{Al}_{2} \mathrm{O}_{3}$ using DRIFTS and Raman has been established. Such a database can provide knowledge to develop a better and more robust NOx adsorber catalyst system. The following examples illustrate the capability of surface analyses to elucidate the NOx and SOx chemistry of model BMOs.

Figure 4a shows the Raman spectrum of nitrated $\mathrm{BaO}$ powder exposed to $\mathrm{NO}_{2}$ (1000 ppm in air) at $250^{\circ} \mathrm{C}$ for 1 hour. The spectral patterns of 1060/690 $\mathrm{cm}^{-1}$ features in Figure 4a match well with the bands observed for $\mathrm{Ba}\left(\mathrm{NO}_{3}\right)_{2}$ crystal. The $848 \mathrm{~cm}^{-1}$ band attributed to $\mathrm{BaO}$ can be used as an internal reference for quantification. Besides these major bands, three additional weak features, observed at 1765, 1506 and $1423 \mathrm{~cm}^{-1}$ can be assigned as surface nitrated species. As shown in the figure, buildups of the bulk species are significantly larger than the surface species. Raman spectra of nitrated $\mathrm{BaO}$ were also studied at various temperatures, ranging from $70^{\circ} \mathrm{C}$ to $250^{\circ} \mathrm{C}$. The buildups of the bulk and surface nitrate species at each temperature were normalized against the integrated strength of the $\mathrm{BaO} 848 \mathrm{~cm}^{-1}$ band. It is evident that the formation of bulk species is overwhelmingly dominant and more or less insensitive to the temperature of studies as indicated in Figure $4 \mathrm{~b}$. It seems that surface nitrate can easily transform into bulk nitrate if sufficient exposure to excess quantity of $\mathrm{NO}_{2}$ occurs. It is generally understood that bulk nitrates are more difficult to reduce than surface nitrates due to their ionic characteristics. It suggests that avoiding formation of bulk nitrate at low temperatures may be important to improve low temperature performance of NOx adsorbers. Based on the current data, we can conclude that nitrate formation is by far the most dominant process in the nitration of BMO's and most of the nitrates are bulk-like.

Figure 5 shows the Raman spectra of sulfated $\mathrm{BaO}$ powder exposed to $\mathrm{SO}_{2}$ (998 ppm in air) at $25^{\circ} \mathrm{C}$ and 
$320^{\circ} \mathrm{C}$ under aerobic condition for one hour. Besides the $\mathrm{BaO}$ band at $848 \mathrm{~cm}^{-1}$, several sulfated species are observed. At $25^{\circ} \mathrm{C}$, the sulfated species are observed at 1685, 1059, 989 and $948 \mathrm{~cm}^{-1}$. The 989 $\mathrm{cm}^{-1}$ band can be assigned as the bulk sulfate while the other bands may be attributed to surface sulfated species. With a ratio to $\mathrm{BaO}$ band at $848 \mathrm{~cm}^{-1}$, all buildups of the sulfated species can be normalized. It is interesting to note that the bulk-sulfate formation (the growth of $989 \mathrm{~cm}^{-1}$ band) only occurs at high temperatures. At low temperatures, very little bulk sulfate was formed. At temperatures below $250^{\circ} \mathrm{C}$, several surface sulfated species can be seen at 948 (sulfite) and $590 \mathrm{~cm}^{-1}$ (bending modes of sulfated species). The $590 \mathrm{~cm}^{-1}$ band is quite broad indicating the presence of a mixture of bending modes. The $1060 \mathrm{~cm}^{-1}$ band can be attributed to a mixture of bisulfate and carbonate. Above $300^{\circ} \mathrm{C}$, the strong sulfate band at $989 \mathrm{~cm}^{-1}$ begins to show and the bending band splits into several sharp features located at 648/618 $\mathrm{cm}^{-1}$ and $491 / 462 / 454 \mathrm{~cm}^{-1}$. Three additional bands are also present at 967,918 and $1570 \mathrm{~cm}^{-1}$. The $967 / 918 \mathrm{~cm}^{-1}$ pair can be attributed to sulfites while the $1570 \mathrm{~cm}^{-1}$ can be attributed to pyrosulfate formation. Pyro-sulfate bands can be easily observed in Raman. High temperatures seem to favor the formation of sulfates and pyro-sulfates. The temperature dependence of the $989 \mathrm{~cm}^{-1}$ band (bulk sulfates) shows a nonlinear response while the increase of $1060 \mathrm{~cm}^{-1}$ band (bisulfates/carbonates) is almost linear. We conclude that the formation of surface species is dominant in sulfation and the surface accumulation is sensitive to temperature.

\section{NOX ADSORBER CHARACTERIZATION}

Catalyst durability is the most critical issue in NOx adsorber development in current aftertreatment technology. Deactivation of NOx adsorbers involves many pathways and S-poisoning is possibly the most recognizable one. Degradation pathways are temperature driven and mostly irreversible in nature, such as the particle size growth of precious metals and the sintering effect of BMOs and/or supporting materials. Some occur at a relatively slow pace, such as the dispersion loss of certain active components. Some may be caused by catalyst fouling due to the incomplete burning of condensed hydrocarbons during the catalyst regeneration. Although catalyst deactivation appears inevitable, it is important to minimize the drastic degradation thus extending catalyst useful life.

Spectroscopic characterization of the inlet portion of catalyst samples following the time sequence of an engine test reveals important information related to catalyst deactivation. Surface changes on catalysts can be characetrized using differential DRIFTS, a subtraction of the spectrum of the fresh sample from the spectrum of an aged sample. Both buildups and depletions are observed in differential DRIFTS.
Depletions correspond to spectral changes of certain functionalities displaced by the reaction gas. Our DRIFTS database for model bulk BMOs provides a basis for band assignment. Major DRIFTS bands of various BMOs are listed in Table III. In nitration, the major spectral changes can be seen in the buildups of nitrates and the loss of surface $\mathrm{OH}$. The $\mathrm{OH}$ loss must be attributed to surface displacement and insertion reactions with NOx. In sulfation, the major spectral changes occur in the growth of sulfates and surface adsorbed $\mathrm{SO}_{2}$ and the loss of $\mathrm{OH}$. The loss of $\mathrm{OH}$ may also be caused by surface insertion and displacement reactions by $\mathrm{SO}_{2}$ or $\mathrm{SO}_{3}$. Typical insertion and displacement reactions of sulfur oxides species are:

$>-\mathrm{OH}+\mathrm{SOx} \rightarrow>-\mathrm{SOxOH}$ and

$\mathrm{BaCO}_{3}+\mathrm{SO}_{2}+1 / 2 \mathrm{O}_{2} \rightarrow \mathrm{BaSO}_{4}+\mathrm{CO}_{2}$

Figure 6 shows the spectra of differential DRIFTS before and after the engine aging of a Barium-based NOx adsorber. As shown in the Figure, a series of relatively sharp features, located at $858,1060,1750$, 2451 and $2822 \mathrm{~cm}^{-1}$, was depleted from the spectrum of the fresh sample. All these bands match well with the spectrum of $\mathrm{BaCO}_{3}$. It is known that the fresh sample equilibrates with the $\mathrm{CO}_{2}$ in the air contributing to abundant $\mathrm{BaCO}_{3}$ absorption bands. Upon exposure to engine exhaust, $\mathrm{BaCO}_{3}$ can be easily converted into $\mathrm{Ba}\left(\mathrm{NO}_{3}\right)_{2}$. Besides the depletion of $\mathrm{BaCO}_{3}$, a significant $\mathrm{OH}$ loss was also observed. Based on the data in Table III, the relatively sharp depletion at $3746 \mathrm{~cm}^{-1}$ in Figure 6 can be attributed to a loss of type III OH's (following the KnozingerRatnasamy classification) associated with $\mathrm{Al}_{2} \mathrm{O}_{3}(30)$. This type of surface OH's appears to have a high reactivity with $\mathrm{SO}_{2}$. The reaction most likely undergoes a formation of bi-sulfates, $>-\mathrm{OH}+\mathrm{SO}_{3}$ $\rightarrow>-\mathrm{OSO}_{2} \mathrm{OH}$.

Several buildups related to nitrated and sulfated species are observed in Figure 6 . The buildup at $1098 \mathrm{~cm}^{-1}$ can be attributed to sulfate formation. There are two types of nitrate formation. The 1376 $\mathrm{cm}^{-1}$ band corresponds to nitrates located on $\mathrm{BaO}$ sites while the $1580 \mathrm{~cm}^{-1}$ band corresponds to nitrates on $\mathrm{Al}_{2} \mathrm{O}_{3}$ sites. All spectral assignments are based on the database collected for model BMOs. Besides sulfate and nitrate formation, weak features at 2960 and $1470 \mathrm{~cm}^{-1}$ can be assigned to $\mathrm{C}-\mathrm{H}$ stretchings and bendings. It suggests that condensed hydrocarbon species are accumulated on the surface of the aged sample, particularly in the later time of engine test.

The DRIFTS spectra as a function of time on stream of the inlet portion of the engine aged NOx adsorber catalyst are presented in Figure 6 . The configuration of the aftertreatment system used in this engine test is also shown in Figure 7. It contains a SOx trap 
followed by a NOx adsorber and then a catalyzed soot filter to remove PM. Diesel fuel was injected after the SOx trap but prior to the NOx adsorber during the regeneration. To minimize the masking effect caused by sulfur poisoning from the fuel, Philips ultra-low $S$ fuel $(<3$ ppm [S]) was used as both the engine and regeneration hydrocarbons. It was determined that the performance of the NOx adsorber lost about 10\% NOx conversion efficiency during 350 hours operation in a light-duty cycle. Three major deactivation pathways are speculated. They are: (1) sulfur poisoning from the fuel during regeneration, (2) incomplete reduction of trapped NOx species, and (3) residuals and coke formation of condensed hydrocarbons from unburned fuel components during regeneration.

Besides the most pronounced $1120 \mathrm{~cm}^{-1}$ band that can be assigned as sulfate formation, the buildup at $1290 \mathrm{~cm}^{-1}$ can be attributed to nitrate formation, particularly on $\mathrm{BaO}$ sites. The Cordierite band at $1860 \mathrm{~cm}^{-1}$ can be used as an internal reference for quantification of the change of absorption band. A couple weak features appearing at 2970 and 3020 $\mathrm{cm}^{-1}$ can be related to hydrocarbon bands, possibly resulted from the condensed fuel derived species.

The assignment of the condensed hydrocarbons can also be verified by Raman spectra between the fresh and the aged sample. Figure 8 shows several Raman features at 251, 564/574, 680, 972/1007 and $1193 \mathrm{~cm}^{-1}$ which can be assigned as Cordierite bands. For aged samples, besides a gradual increase of the fluorescence background, two major bands are observed at 1360 and $1588 \mathrm{~cm}^{-1}$ which can be assigned as the typical carbon bands. The fluorescence comes from the aromatic residual of the condensed hydrocarbon species. The intensity ratio between these two carbon bands reflects the aromatic domain size. The Raman nature of these carbon bands has been extensively studied for various carbonaceous materials (37-38). Many excellent reviews have been reported and various phonon models have been developed (39). The Raman ratio between the disordered (the $1350 \mathrm{~cm}^{-1}$ band) and the graphitic band (the $1588 \mathrm{~cm}^{-1}$ band) has been used as a measure for the growth of microcrystallite. It is a good indicator of formation of coke precursor.

Temporal buildups of nitrates, sulfates and hydrocarbons are listed in Figure 9. Nitrate buildup seems to slow down after 200 hrs of operation. Besides a rapid increase at the beginning, the sulfate buildup increases continuously in intensity with time. Further reactions of surface oxy-sulfur species to form pyro- or poly-sulfates following the reactions of $>-\mathrm{OH}+\mathrm{SO}_{3} \rightarrow>-\mathrm{OSO}_{2} \mathrm{OH}$ and $2>-\mathrm{OSO}_{2} \mathrm{OH} \rightarrow$ $\mathrm{S}_{2} \mathrm{O}_{7}{ }^{2}+\mathrm{H}_{2} \mathrm{O}$ or $2 \mathrm{HSO}_{3}{ }^{-} \rightarrow \mathrm{S}_{2} \mathrm{O}_{5}{ }^{2}+\mathrm{H}_{2} \mathrm{O}$ may account for the continuous buildups. The overall buildups of hydrocarbons also grow with time. However, the non- uniformity of the burning of the injected fuel during operation gives rise to fluctuations in hydrocarbon deposit.

The measured IR buildup (the integrated strength of the specific absorption band) of surface adsorbing species generally relates to the remaining sites available for further adsorption. According to the Elovich adsorption mechanism (40), the surface buildup of a specific species $q$ at a time $t$ may follow an equation of $d q / d t=k \exp (-\beta q)$, where $k$ is the adsorption rate and $\beta$ is a constant, more or less, independent of pressure and temperature. Since the NOx conversion efficiency of a NOx adsorber is proportional to the available adsorption sites on the catalyst surface, the available sites at a time $t$ gradually diminishes if poisons start to occupy the sites. The density of the sites should follow an exponential decay if Elovich adsorption mechanism applies. The NOx conversion efficiency is proportional to the available active sites on catalyst surface,

$$
\begin{aligned}
N(\text { available sites }) & \propto N_{0} \exp \left(-\left[\alpha_{S}+\alpha_{N}+\alpha_{C}\right] t\right) \\
& \propto N_{0} \exp \left(-\alpha_{\text {all }} t\right),
\end{aligned}
$$

where $\mathrm{N}_{0}$ is the total adsorption sites of a fresh catalyst, $\alpha_{S}$ is the degradation coefficient for $S$ poisoning, $\alpha_{N}$ is the degradation coefficient for incomplete regeneration of trapped NOx sites, and $\alpha_{C}$ is the degradation coefficient for coke formation and other sintering effects. For simplicity, all thermal instability and sintering effects of $\mathrm{Pt}$ and supporting materials can be grouped within the term of $\alpha_{c}$.

Assuming all the structural changes caused by $\alpha_{S}, \alpha_{N}$ and $\alpha_{C}$ under the operating conditions are irreversible and independent among one another, the time dependent adsorption kinetics will be

$$
k N_{0} \exp \left(-\alpha_{i} N\right)=d N / d t \text { for each adsorbed species. }
$$

With an integration of

$$
\left.\int \exp \left(\alpha_{i} N\right)\right) d N=N_{0} \int k d t,
$$

a linear relationship of $\alpha_{i} \propto \ln (t)$ can be obtained. In IR measurement, $\alpha$ is directly proportional to the absorbance (the integrated signal of a specific functionality). As shown in Figure 8, both nitrate and sulfate buildups exhibit a linear response to $\ln (t)$. The slopes for such linear dependence, $\alpha \propto \ln (\mathrm{t})$, are also found quite similar suggesting a similar mechanism for surface adsorption. We conclude that most IR buildups on NOx adsorber follow Elovich surface adsorption mechanism.

\section{SOx TRAP CHARACTERIZATION}




\section{SOx TRAP CHARACTERIZATION}

Besides the common poisons from fuel, lubricant additives may also contribute to catalyst deactivation. A typical example is the anti-wearing component, ZDDP in oils, can deposit phosphates on the catalyst. Phosphate species have been identified in the front side of the aged SOx trap that is placed upstream of the NOx adsorber. Figure 10 shows DRIFTS spectra of an aged SOx trap as a function of time on stream. The configuration of the aftertreatment system is identical to the one depicted in Figure 6 where the soot filter is located downstream. Two characteristic phosphate bands at 1260 and $1605 \mathrm{~cm}^{-1}$ match reasonably well with the spectrum of the aged SOx trap after $260 \mathrm{hr}$ of operation. The phosphoruscontamination is not observed in the backside of SOx trap indicating a strong surface adhesive nature for phosphates. With a comparison to the spectrum of zinc phosphate, the band at $1260 \mathrm{~cm}^{-1}$ is slightly shifted to higher energy, indicating a mixture of other phosphate salts including calcium. Whether these phosphate species exhibit detrimental impacts on SOx trap remains to be seen. The phosphorus and ash components from lubricants can be identified in aged catalysts. As shown in Figure 10, the phosphate buildup is not significant at the early time $(\sim 50 \mathrm{hr})$, but grows with a faster rate than sulfates.

\section{SULFUR MANAGEMENT}

Sulfur poisoning from the fuel is the most recognizable degradation mechanism in NOx adsorber technology. SOx competes for the active sites available for NOx adsorption to form thermodynamically more stable sulfate species. The sites covered by these sulfated species are difficult to regenerate at normal operation temperatures (e.g. < $500^{\circ} \mathrm{C}$ ). Even with the availability of $15 \mathrm{ppm}$ sulfur diesel fuel, NOx adsorber will be totally deactivated without effective sulfur management. In addition to fuel sulfur, sulfur in the lube oil also plays a role in sulfur loading and performance degradation in NOx adsorber.

Two general pathways are currently being explored for sulfur management: (1) the use of a disposable SOx trap that can be replaced or rejuvenated offline periodically, and (2) the use of diesel fuel and high temperature desulfation strategy to desorb the sulfates in order to recover the NOx trapping efficiency. The advantages and disadvantages of both approaches are briefly compared below.

High adsorption capacity and high selectivity for sulfur are the main driving forces for the design of disposable SOx trap. It provides a protection of adsorber catalyst from sulfur poisoning during misfueling which may be an important aspect in the near future. The relatively small size and economic cost are attractive for light-duty applications even with a restriction of limited lifetime. Usable lifetime of SOx trap is dependent on sulfur level in the fuel and the lube. Designed properly, it would not release any significant secondary emission.

For desulfation approach, the catalytic system requires on-board management to generate a high temperature exhaust (e.g. $\left.>600^{\circ} \mathrm{C}\right)$ to release sulfur from the catalyst. It is obvious that secondary emissions, such as hydrogen sulfide and/or sulfur dioxides, will be major concerns. Fuel penalty will be another hurdle that can not be avoided during desulfation. The main advantage is the integration of both trapping functions of NOx and SOx together. Therefore the development requires compromise among NOx storage \& conversion, SOx storage \& release, and catalyst thermal durability.

In the current development program, one of the efforts was focused on developing a SOx trap with sufficient capacity to protect the NOx adsorber catalyst for at least 20,000 miles operation. The SOx trapping efficiency needs to be maintained near $100 \%$ all the time (<10 ppb break-through), and the stored SOx should not be released during the hottest driving conditions and the rich condition for NOx regeneration. The current development path employs a formulation containing base metals. A SOx trap with a capacity of $20 \mathrm{gm} \mathrm{SO}_{2} / \mathrm{l}$ and an estimated 15,000 mile lifetime before change-out has been demonstrated in the laboratory. Alternate substrates with high pore volume to improve its capacity are under investigation.

\section{FUTURE WORK AND DIRECTION}

Significant progress in NOx adsorber technology has been made in this program, but much work still remains to be accomplished. As mentioned previously, sulfur management is one of the most critical areas where progress still needs to be focused in order to make the NOx adsorber technology plausible. The capacity of a replaceable or off-line regenerable SOx trap needs to be increased to achieve an acceptable service interval. Alternatively, regenerable NOx adsorbers that allow the trapped SOx to be released at high temperatures need to be explored. Durability of a NOx adsorber exposed to periodic high temperature regeneration for SOx removal must be addressed and demonstrated.

Effective use of reductants introduced to the exhaust to optimizing catalyst conversion efficiency and minimizing fuel penalty needs to be emphasized. Reductant dispersion and concentration are important parameters when selecting placement and spray characteristics of an auxiliary injector.

High NOx reduction has been demonstrated through current development efforts. However, a system with acceptable cost has not yet been achieved. Efforts to reduce the size and complexity of the catalyst 
system, thereby reducing the overall cost need to continue. Catalyst size reduction and integration should be investigated. Washcoat formulations and substrate geometry and materials are under consideration to further optimize the aftertreatment system.

While NOx control is one of the main concerns with respect to emissions controls on diesel engines, one does not wish to inadvertently produce any potentially harmful unregulated byproducts as a result of the addition of any new aftertreatment devices. The potential of ammonia $\left(\mathrm{NH}_{3}\right)$ generation from adsorbers when $\mathrm{HC}$ is injected during regeneration needs to be evaluated.

Component and system reliability and durability have not yet been investigated thoroughly. Both component and system reliability and durability are of great interest to both the manufactures and regulatory agencies. In continuing development efforts, we will keep a close watch on any indicators such as failures or performance deterioration to provide some insight into component and system capability.

\section{CONCLUSIONS}

- $\quad$ Spectroscopic techniques, DRIFTS and Raman are valuable tools in catalyst characterization in elucidating the NOx storage and aging mechanisms of NOx adsorber catalyst.

- $\quad$ Surface adsorbing species responding to temperature and temporal behaviors provide kinetics information.

- Reforming of on-board diesel fuel to syngas may provide an effective way to enhance low temperature performance of NOx adsorber.

- The integrated IR buildups of surface nitrate and sulfate species with time on stream suggests an Elovich adsorption mechanism.

- S-contamination, incomplete regeneration and coke formation are responsible for the loss of low temperature performance of NOx adsorber catalyst even when an ultra low-S fuel (<3ppm [S]) is used. - Oil-derived contaminants such as phosphates and metal ash have been observed and their impacts on catalyst performances are under investigation.

\section{ACKNOWLEDGMENTS}

The authors gratefully acknowledge the support by the Department of Energy (Contract DE-FC0299EESOS77) and Cummins Inc. Contributions from colleagues Scott Cole, Thomas Gallant, Jerry Wang and Jian Li, for their help in making this paper possible, are appreciated.

\section{REFERENCES}

1. Hsiao, M.C., Merritt, B.T., and Voigtlin, G.E., "Fundamentals Limits on Gas-Phase Chemical Reduction of $\mathrm{NO}_{x}$ in a Plasma", Diesel Engine Emissions Workshop, July, 1997; Hsiao, M.C., Penetrante, B.M., Merritt, B.T. and Voigtlin, G.E., "Plasma Assisted Heterogeneous Catalysis for $\mathrm{NO}_{x}$ Reduction in Lean-burn Engine Exhausts", ibid. 1997

2. Penetrante, B.M., Brusasco, R.M., Merritt, B.T., Pitz, W.J., Vogtlin, G.E., Kung, M.C., Kung, H.H., Wan, C.Z. and Voss, K.E., "Plasma Assisted Catalytic Reduction of NOx", SAE982508; Hammer, T. and Broer, S., "Plasma Enhanced Selective Catalytic Reduction of $\mathrm{NO}_{x}$ for Diesel Cars", SAE982428, 1998

3. Penetrante, B.M., "Limiting Factors and Effect of Sulfur on Plasma-Assisted Catalytic Reduction of $\mathrm{NO}_{x}$ in Light-Duty Vehicle Exhaust", Diesel Engine Emissions Workshop, July, 1999; Penetrante, B.M., Brusasco, R.M., Merrit, B.T. and Vogtlin, G.E., "Sulfur Tolerance of Selective Partial Oxidation of $\mathrm{NO}$ to $\mathrm{NO}_{2}$ in Non-Thermal Plasma for Exhaust Emission Control: $\mathrm{NO}_{x}, \mathrm{HC}$, and Particulates", SAE1999-01-3687, 1999

4. Konig, A, et al., "Research Results on Processes and Catalyst Materials for Lean $\mathrm{NO}_{x}$ Conversion", SAE962041, 1996

5. Arakawa, K., Matsuda, S. and Kinoshita, H., "Progress in Sulfur Poisoning Resistance of Lean $\mathrm{NO}_{x}$ Catalysts", SAE980930, 1998

6. Iwasaki, M., Ikeya, N., Itoh, M. and Itoh, M., "Development of Zeolite Catalyst to Remove Diesel NO $"$ ", SAE958386, 1995

7. Bunting, B.G., Cunningham, M.J. and Miller, R.K., "A Diesel Perspective on Lean $\mathrm{NO}_{x}$ Catalysts", Diesel Engine Emissions Workshop, July, 1998

8. Mital, R., Huang, S.C, Stroia, B.J., Yu, R.C. and Wan, C.Z., "A Study of Lean $\mathrm{NO}_{x}$ Technology for Diesel Emission Control", SAE2002-01-0956, 2002

9. Miller, R.K., Cunningham, M.J. and Ren, S., "Future Application of Catalyzed Soot Filters", Diesel Engine Emissions Workshop, July, 1998

10. Farrauto, R.J. and Mooney, J.J., "Effects of Sulfur on Performance of Catalytic Aftertreatment Devices", SAE920557, 1992

11. Mooney, J. and Wolfgang, J., "Save the Diesel Fueled Engine: A Clean Diesel Engine with Catalytic Aftertreatment-The alternative to Alternative Fuels", April, 1993

12. Popuri, S., et al., "Development of a Microwave Assisted Regeneration System for A Ceramic Diesel Particulate Trap System", SAE1999-013565, 1999 
13. Nixdorf, R.D., et al., "Microwave-regenerated Diesel Exhaust Particulate Filter", SAE2001-010903, 2001

14. Cooper, B.J. and Thoss, J.E., "Role of NO in Diesel Particulate Emission Control", SAE 890404, 1989

15. DECSE, 2000a. "Phase I Interim Data Report No. 4: Diesel Particulate Filters", U.S. DOE, January, 2000

16. Cunningham, M.J., "NOx Adsorber Catalysts Applied to Heavy Duty Diesel Test Cycles", Diesel Engine Emissions Workshop, July, 1999

17. Guyon, M., Blejean, F., Bert, C. and Le Faou, P., "Impact of Sulfur on $\mathrm{NO}_{x}$ Trap Catalyst activity - Study of the Regeneration Conditions", SAE982607, 1998

18. Kobayashi, S., Nakajima, T. and Hori, M. "Effect of Fuel Sulfur and Aromatics on Diesel Exhaust Emissions", SAE918221, 1991

19. Sumiya, S., Makino, S. and Ogasawara, K., "Catalytic $\mathrm{NO}_{X}$ Reduction by Diesel Fuel Spray Method", SAE4-14-2-82, 1993

20. Bailey, O., Dou, D. and Denison, G.W., "Regeneration Strategies for $\mathrm{NO}_{\mathrm{x}}$ Adsorber Catalysts", SAE972845, 1997

21. Armor, J.N., Appl.Catal. B:Environ. 1, 221, 1992; Fritz, A. and Pitchon, V., ibid. 13, 1, 1997

22. Heck, R.M. and Farrauto, R.J., "Catalytic Air Pollution Control-Commercial Technology", Van Nostrand Reinhold, New York, 1995

23. Heck, R.M., Catal. Today 53, 519, 1999; Forzatti, P., ibid. 62, 51, 2000

24. Coronado, J.M. and Anderson, J.A., J. Mol. Catal. A138, 1999

25. Rodriguez, J.A., Jirsak, T. and Hrbek, J., J. Phys. Chem. B103, 1966, 1999; Mitchell, M.B., Sheinker, V.K. and White, M.G., ibid. 100, 7550, 1996; Waqif, M., Lavalley, J-C, Perathoner, S. and Centi, G., ibid. 95, 4051, 1991

26. Captain, D.K. and Amiridis, M.D., J. Catal. 184, 377, 1999; Fridell, E., Skoglundh, M., Westerberg, B., Johansson, S. and Smedler, G., ibid. 183, 196, 1999; Kijlstra,S., Brands, D.S., Poels, E.K.. and Bliek, A., ibid. 171, 208, 1997; Centi, G., Perathoner, S., Biglino, D. and Giamello, E., ibid. 151, 75, 1995

27. Grasselli, J.G. and Bulkin, B.J., "Analytical Raman Spectroscopy", Wiley, New York, 1991

28. Weber, W.H., "Raman Application in Catalysts for Exhaust Gas Treatment in Raman Scattering in Materials Science", ed. by Weber, W.H. and Merlin, R., Springer, Berlin, 2000

29. Wachs, I.E., Catal. Today 27, 437, 1996

30. Knozinger, H. and Ratnasamy, P., Catal. Rev. Sci. Eng. 17, 31, 1978

31. Matsumoto, S., Catal. Today 29, 43, 1996; Takahashi, N., ibid. 27, 63, 1996; Meunier, F.C.,
Zuzaniuk, V., Breen, J.P., Olsson, M. and Ross, J.R., ibid. 59, 287, 2000

32. Waqif, M., Bazin, P., Saur, O., Lavalley, J-C, Blanchard, G. and Touret, O., Appl. Catal. B11, 193, 1997; Matsumoto, S., Ikeda, Y., Suzuki, H., Ogai, M. and Miyoshi, N., ibid. B25, 115, 2000

33. Waqif, M., Saad, A.M., Bensitel, M., Bachelier, J., Saur, O. and Lavalley, J-C, J. Chem. Soc. Faraday Trans., 88, 2931, 1992; Busca, G., Ramis, G., Lorenzelli, V., Janin, A. and Lavalley, J-C, Spectrochim. Acta 43A, 489, 1987; Degen, I.A. and Newman, G.A., Spectrochim. Acta. 49A, 859, 1993

34. Twu, J., Chuang, C.J., Chang, K.I., Yang. C.H. and Chen, H., Appl. Catal. B12, 309, 1997

35. Kobayashi, T., Yamada, T. and Kayano, K., SAE970745, 1997

36. Miyoshi, N., Matsumoto, S., Tanaka, K., Harada, J., Takahashi, J., Yokota, N., Sugiura, M. and Kasahara, K., SAE950809, 1995

37. Tuinstra, F. and Koenig, J.L., J. Chem. Phys. 53, 1126, 1970; Sood, A.K., Gupta, R. and Asher, S.A., Phys. Rev. B, 2001

38. Kelemen, S.R. and Fang, H.L., Energy \& Fuels 3, 653, 2001; Roberts, S., Tricker, P.M. and Marshall, J.E., Org. Geochem. 23, 223, 1995

39. Nemanich, R.J. and Solin, S.A., Phys. Rev. B20, 392, 1979; Mathews, M.S., Pimenta, M.A., Dresselhaus, G., Dresselhaus, M.S. and Endo, M., ibid. 59, 6585, 1999

40. Thomas, J.M. and Thomas, W.J., "Principles and Practice of Heterogeneous Catalysis", VCH, New York (1997)

\section{ACRONYMS}

$\mathrm{P} / \mathrm{Q} / \mathrm{R}$ : rotational contours of a defined molecular vibration; $P, Q$ and $R$ refer to rotational transitions with change of angular momentum quantum number $\Delta \mathrm{J}=-1,0$ and +1 , respectively.

ABS: stands for absorbance, which is defined as $\ln \left(I_{0} / I\right) ; I$ and $I_{0}$ are intensities of the transmitted and the incident beams.

$\mathrm{OH}$ : hydroxyl group with bending and stretching vibrations around 1630 and $3200 \sim 3700 \mathrm{~cm}^{-1}$.

Chemicals: $\mathrm{BaO}$ (Barium Oxide), $\mathrm{BaCO}_{3}$ (Barium Carbonate), $\mathrm{Ba}\left(\mathrm{NO}_{3}\right)_{2} \quad$ (Barium nitrate), $\mathrm{CaO}$ (Calcium Oxide), $\mathrm{Al}_{2} \mathrm{O}_{3}$ (Aluminum Oxide) 
Table III Major IR functionalities of model metal oxides

$\underline{\mathrm{A}}_{2} \underline{\mathrm{O}}_{3}$

Nitration

Nitrates $\left(\mathrm{cm}^{-1}\right)$

1580

1250/1320/1470

$1350 / 1460$

OHchange $\left(\mathrm{cm}^{-1}\right)$ sharp loss @3750

broad loss@3400

sharploss@3631

broadgrowth@3600 sharp growth@3560/3610

sharp growth@3576

Sulfation

Sulfates $\left(\mathrm{cm}^{-1}\right)$

1150

$1080 / 1190$

$\mathrm{SO}_{2}\left(\mathrm{~cm}^{-1}\right)$

1358

1358

OHloss $\left(\mathrm{cm}^{-1}\right)$ sharp loss @3755/3681 broad loss @3500/3300 

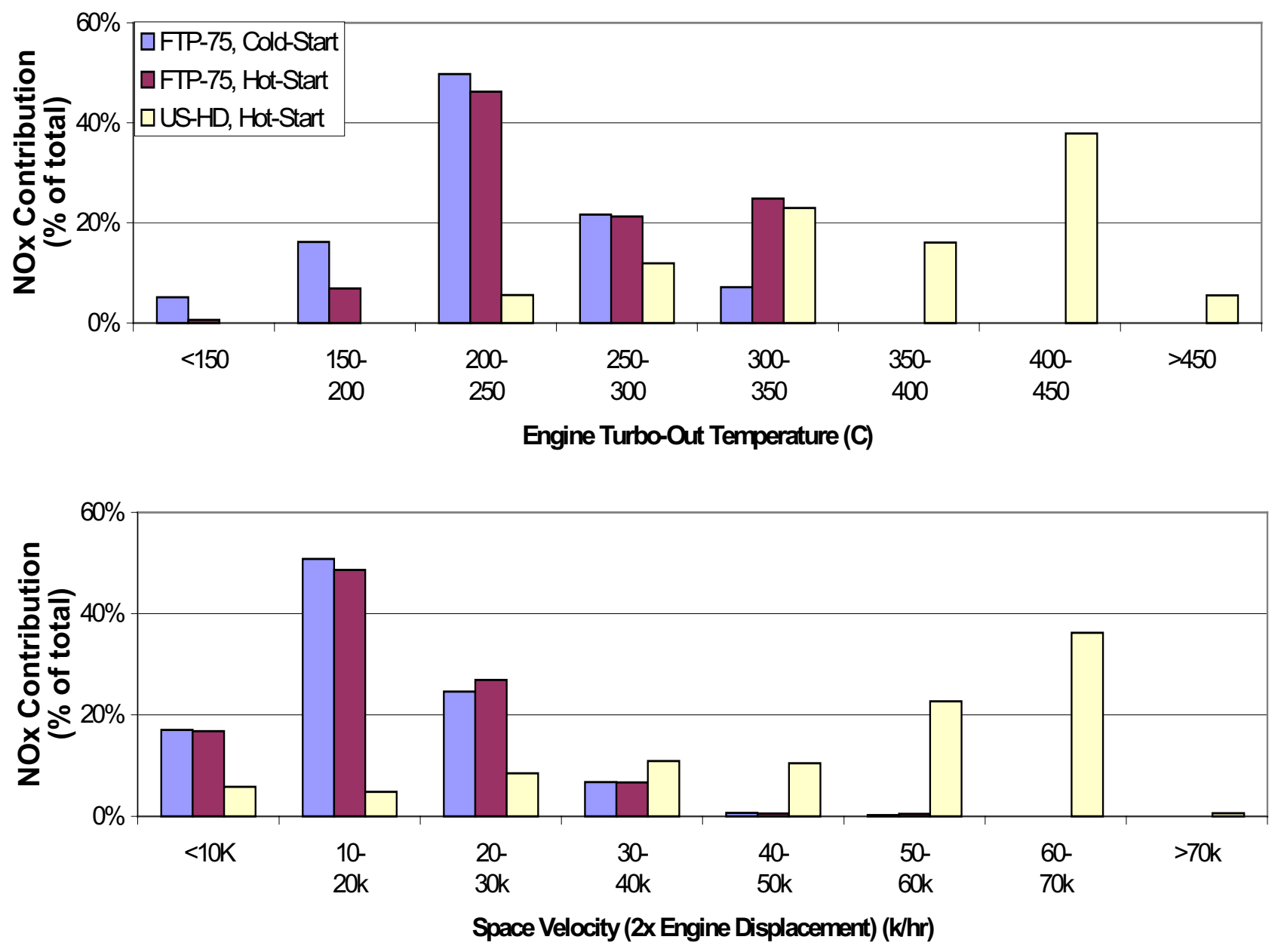

Figure 1 Engine-out NOx contribution vs. engine turbo-out temperature and space velocity. 

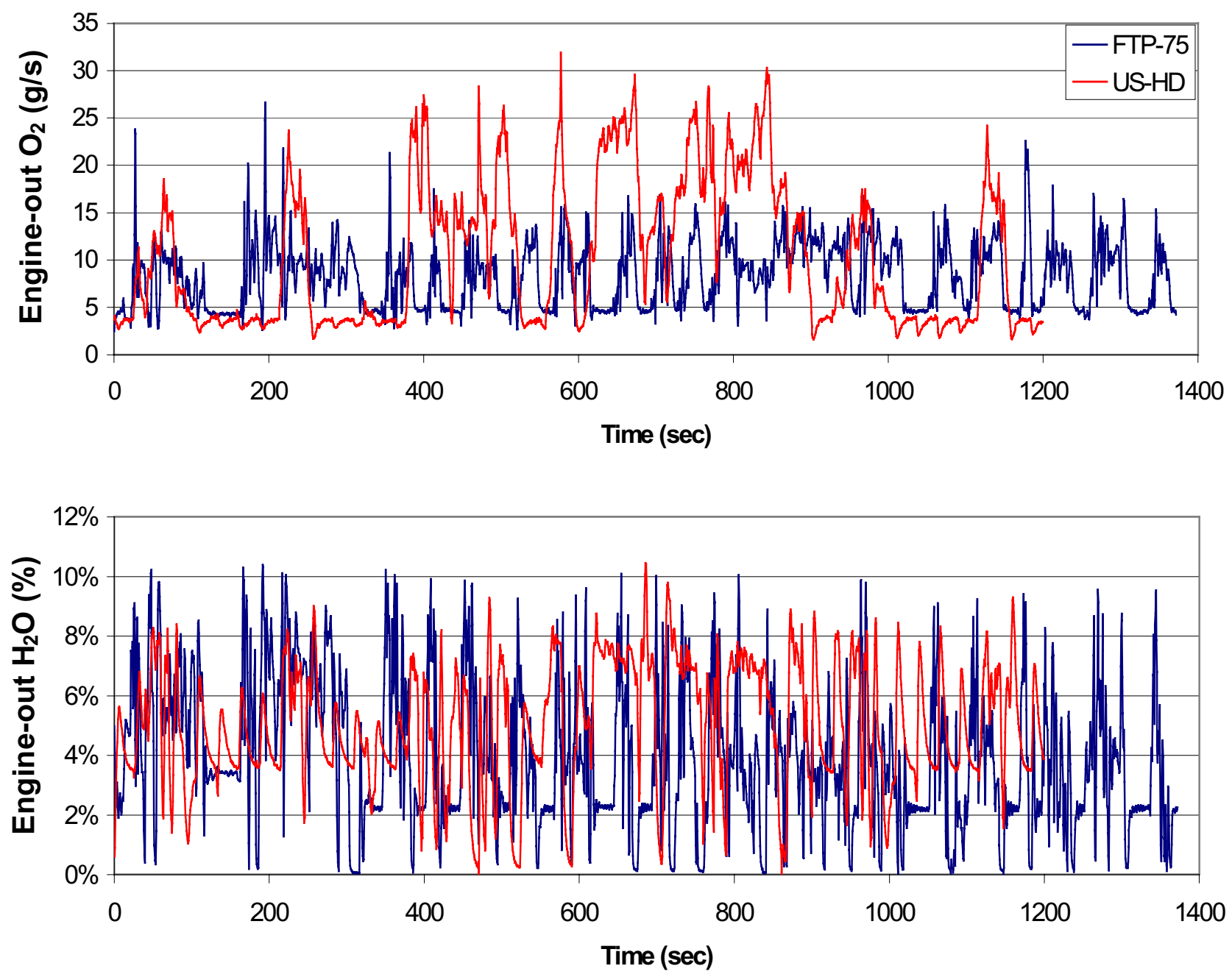

Figure 2 Engine out $\mathrm{O}_{2}$ flow rate and $\mathrm{H}_{2} \mathrm{O}$ concentration history over FTP-75 and US-HD cycles. 
(a)

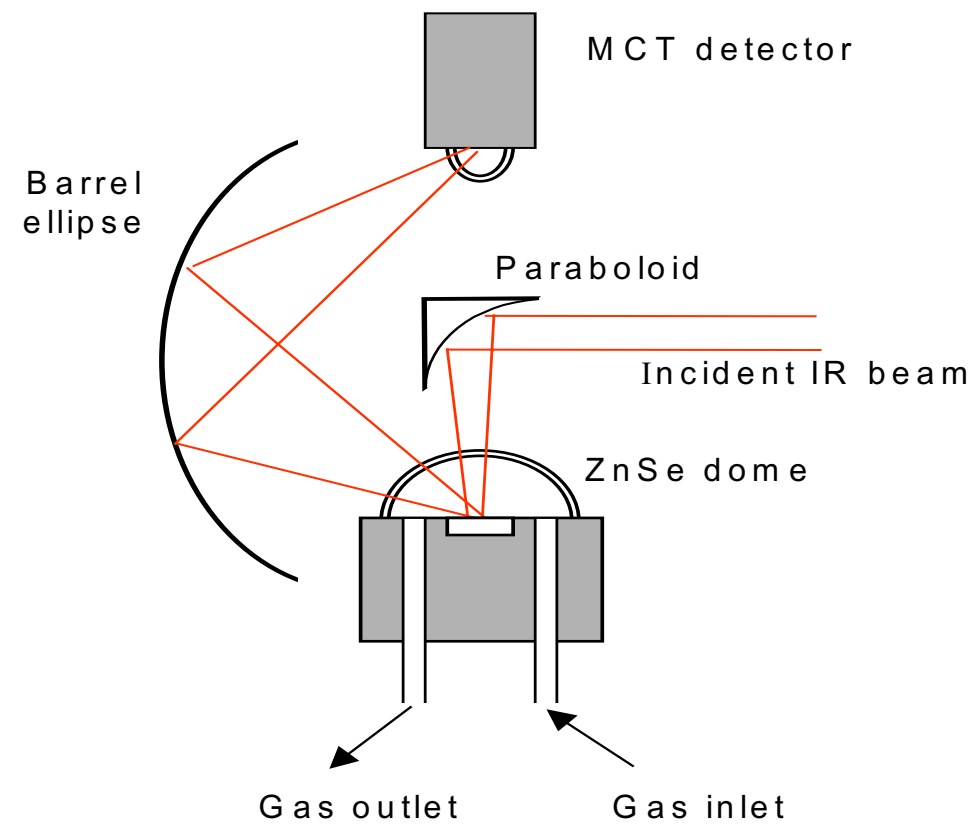

(b)

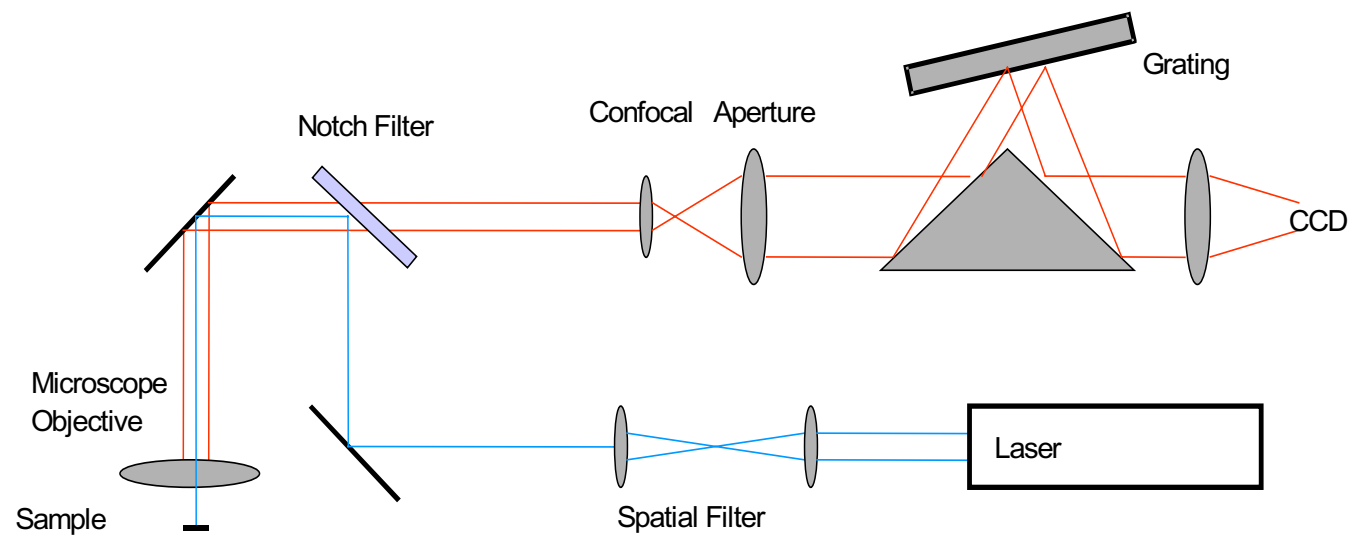

Figure 3 Experimental setups for (a) DRIFTS and (b) MicroRaman 

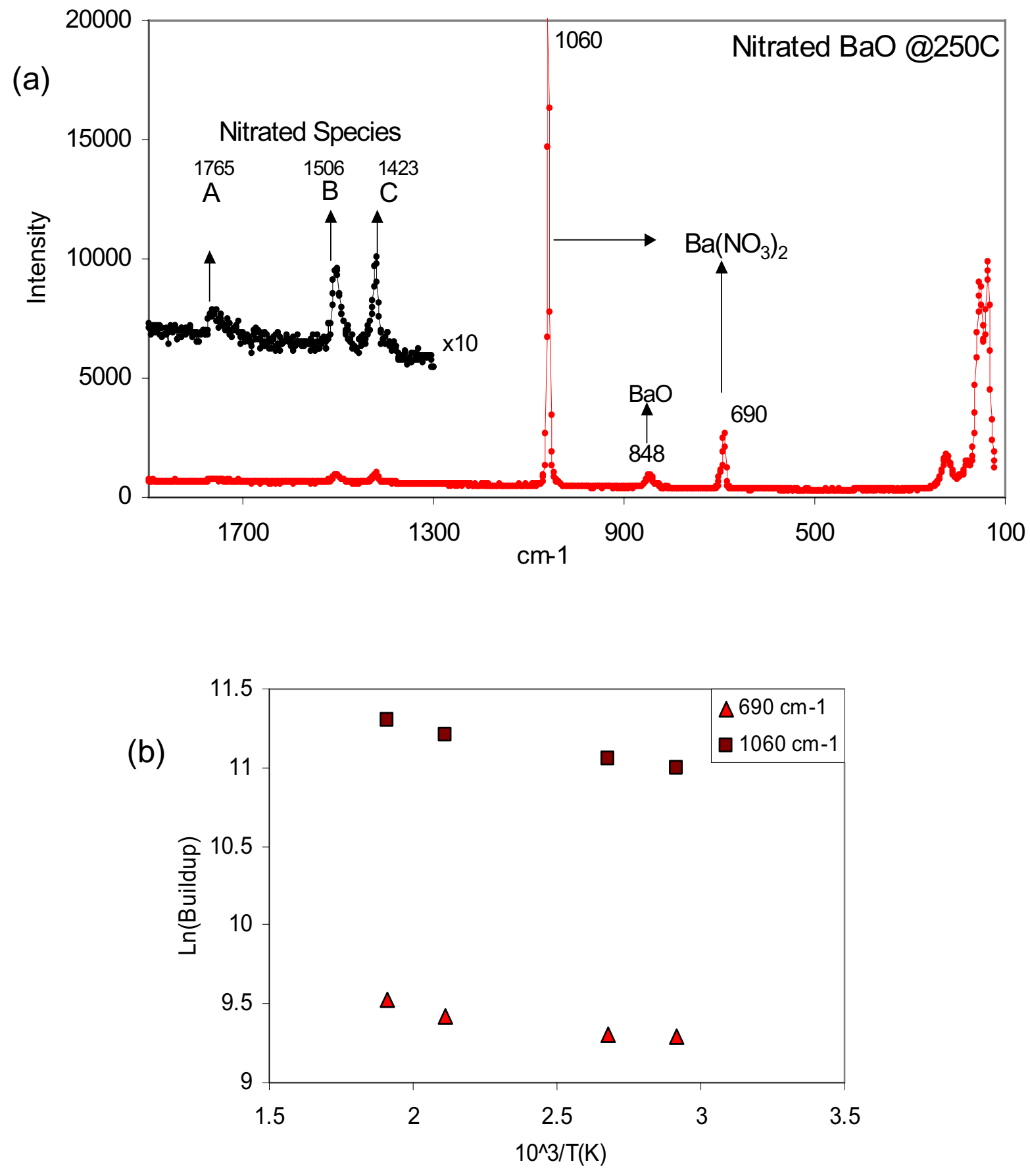

Figure 4 Raman response of nitrated species on BaO: (a) spectrum of $\mathrm{BaO}$ powder exposed to $\mathrm{NO}_{2}$ (1000 ppm in air) at $250^{\circ} \mathrm{C}$ for $1 \mathrm{hr}$ and (b) a plot of nitrate buildups as a function of temperature. All spectra were normalized against $\mathrm{BaO}$ band at 848 $\mathrm{cm}^{-1}$. 


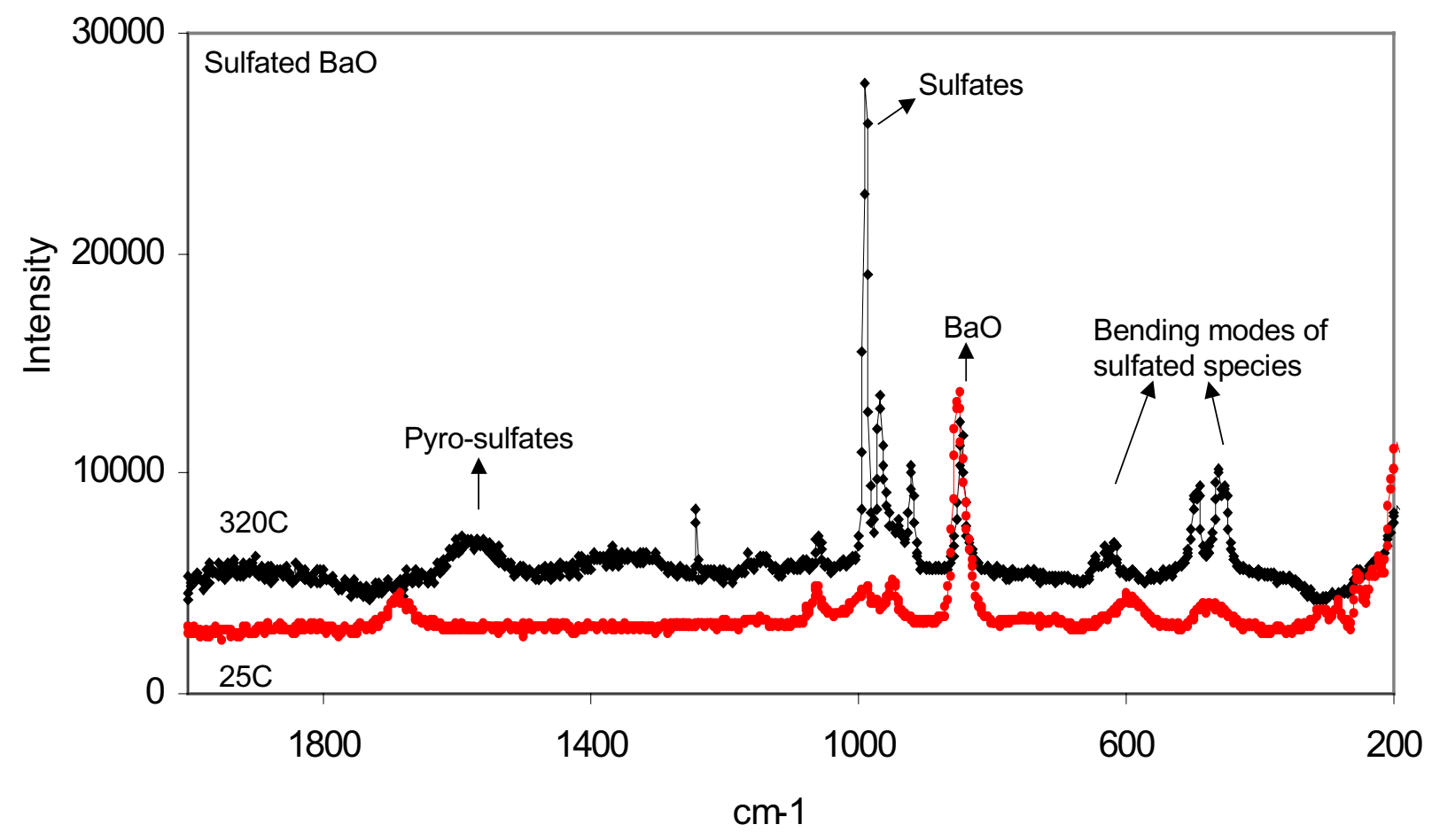

Figure 5 Raman spectra of $\mathrm{BaO}$ powder exposed to $\mathrm{SO}_{2}$ (998 ppm in air) at $320^{\circ} \mathrm{C}$ and $25^{\circ} \mathrm{C}$ for $1 \mathrm{hr}$. 


\section{Differential IR (used@350hr - fresh) of Sample A}

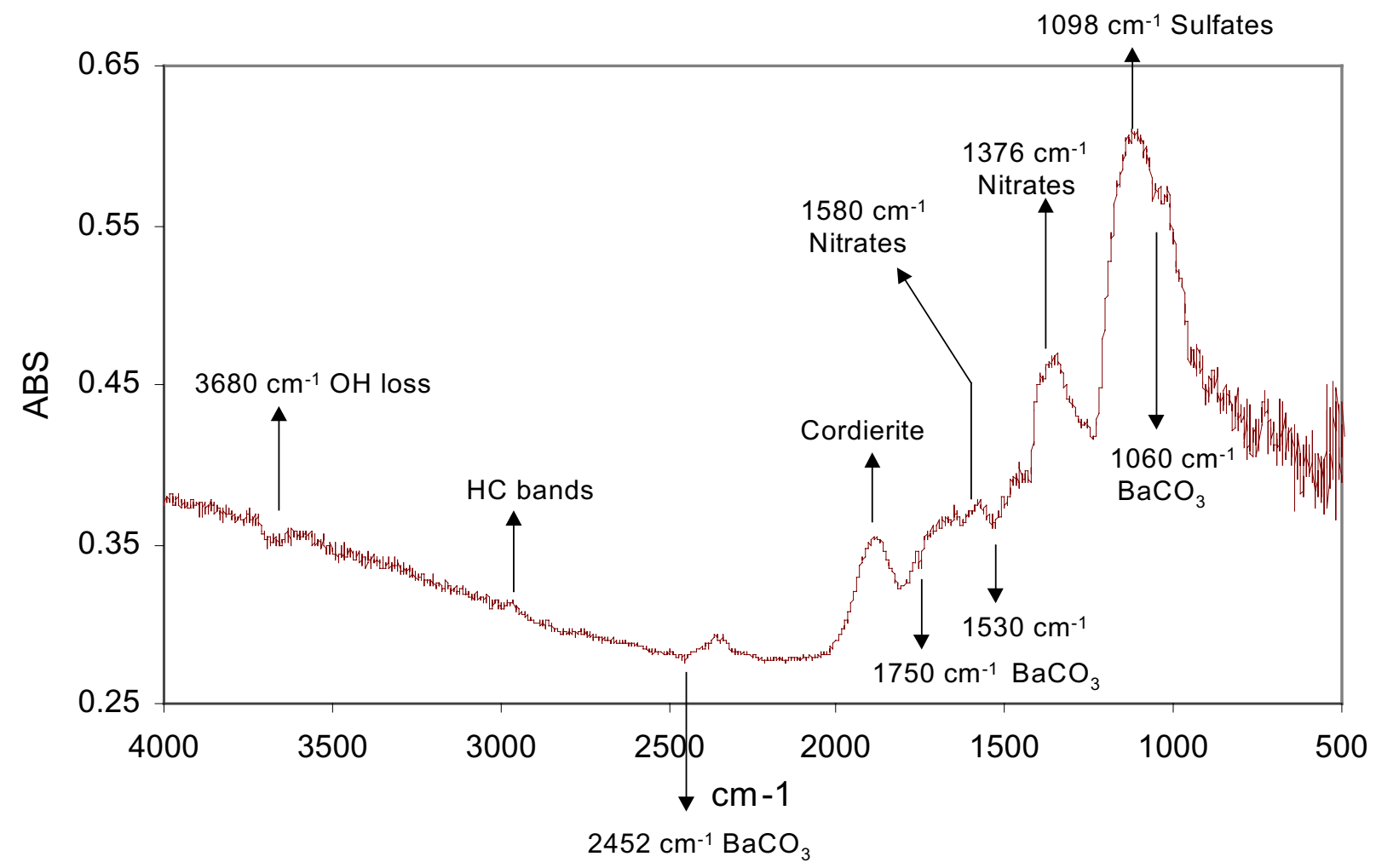

Figure 6 Differential DRIFTS spectrum (absorbance of $350 \mathrm{hrs}$ aged - absorbance of fresh) of an engine aged NOx adsorber. 


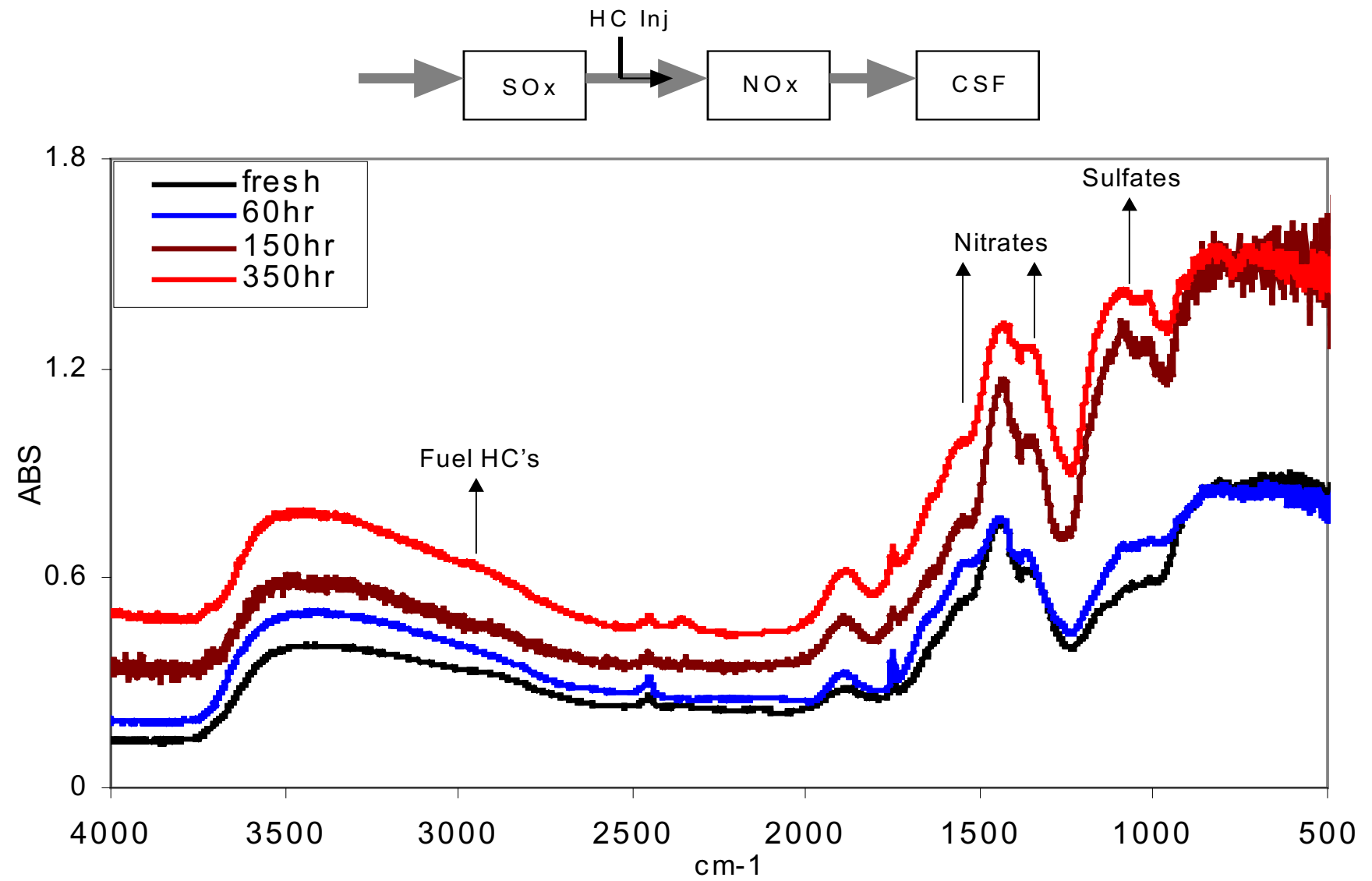

Figure 7 DRIFTS analysis of engine aged NOx adsorber as a function of time on stream. The configuration of the aftertreatment system is shown in the top of the figure where the soot filter is located downstream. 


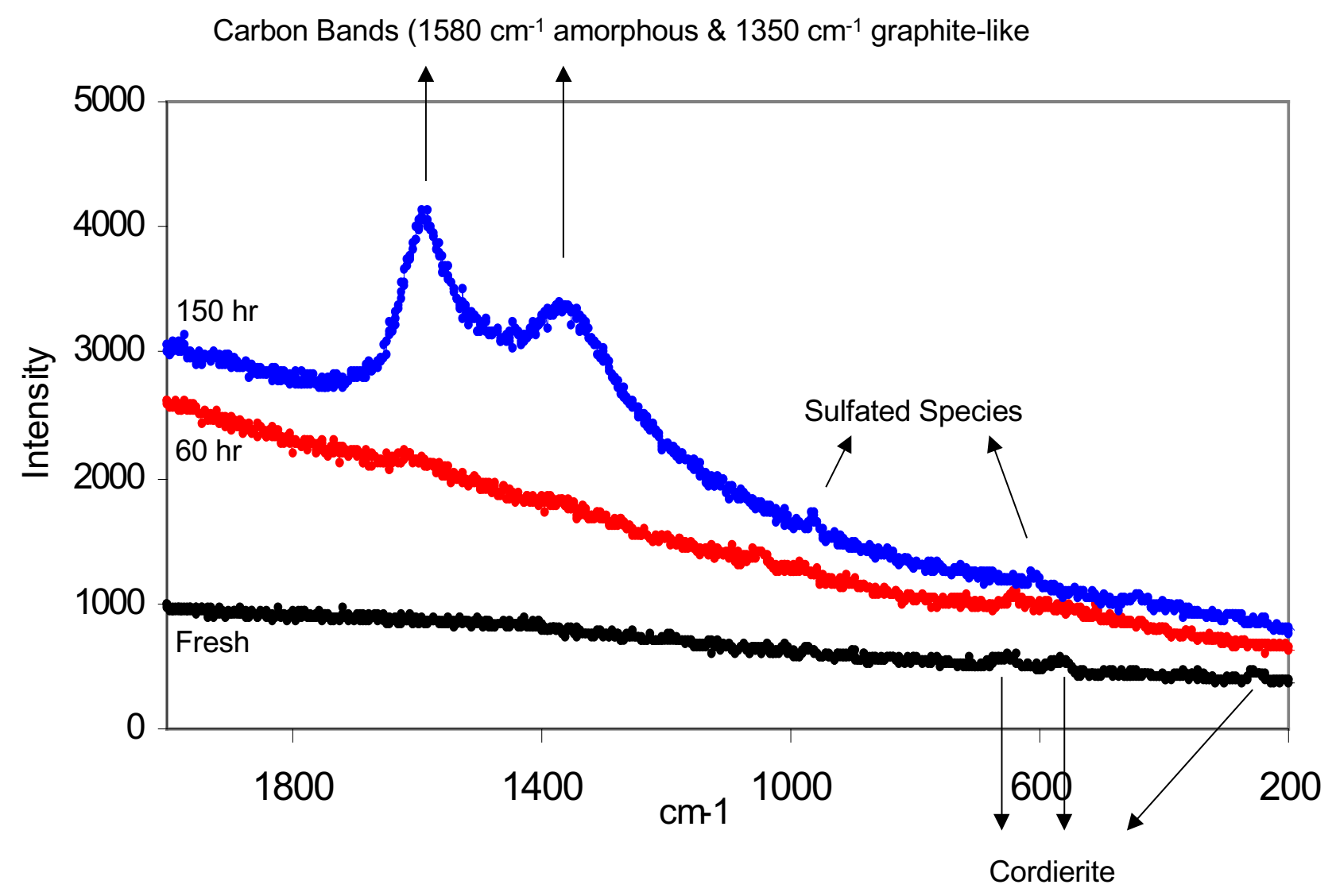

Figure 8 Raman analysis of engine aged NOx adsorber as a function of time on stream. 
(a)

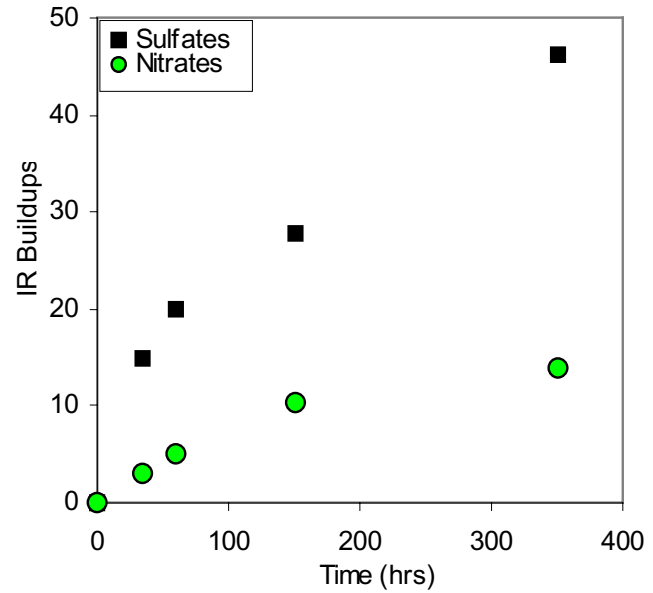

(c)

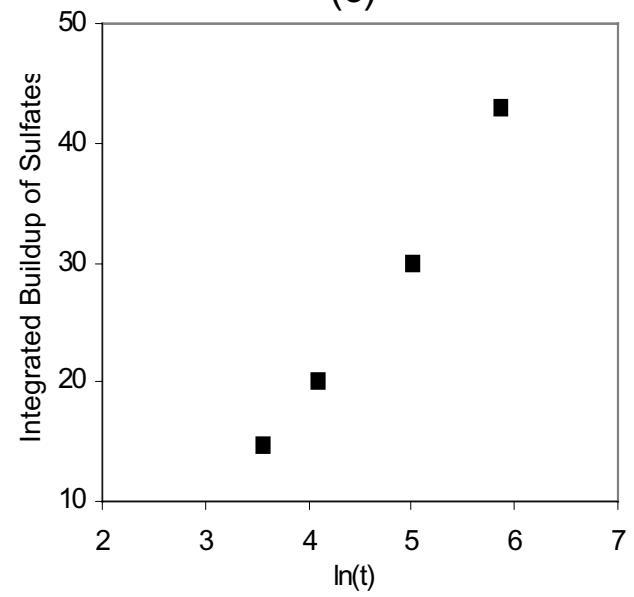

(b)

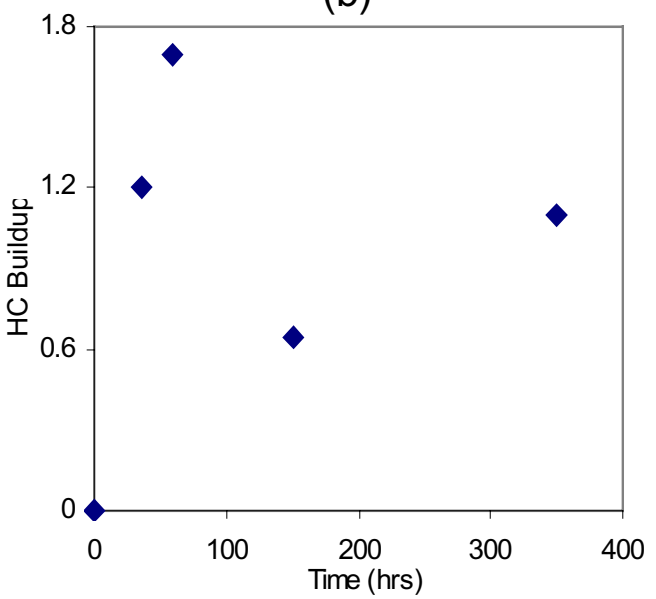

(d)

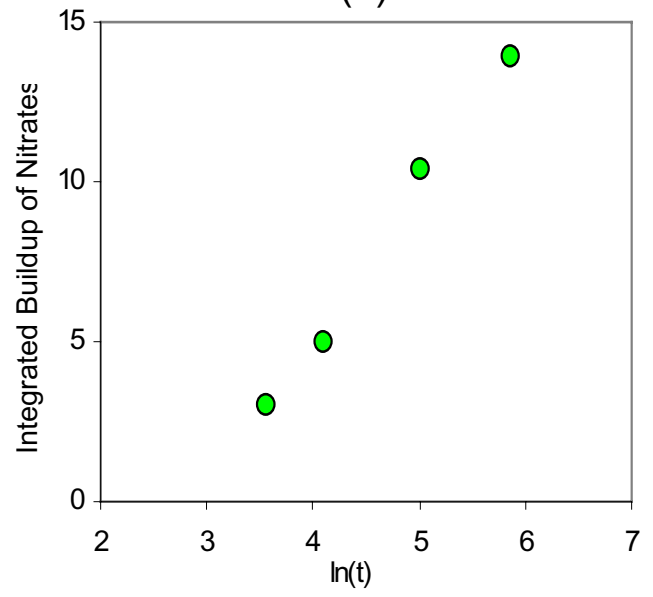

Figure 9 Buildups of surface nitrated and sulfated species of an engine aged NOx adsorber as a function of time:

(a) Buildups of nitrates @1320 cm $\mathrm{cm}^{-1}$ and sulfates @ $1100 \mathrm{~cm}^{-1}$

(b) Fluctuation of hydrocarbon buildups @2970 $\mathrm{cm}^{-1}$

(c) Elovich relationship of sulfate buildups @ $1100 \mathrm{~cm}^{-1}$; (buildups) $\propto \ln (\mathrm{t})$

(d) Elovich relationship of nitrate buildups @1320 $\mathrm{cm}^{-1} ;$ (buildups) $\propto \ln (\mathrm{t})$ 


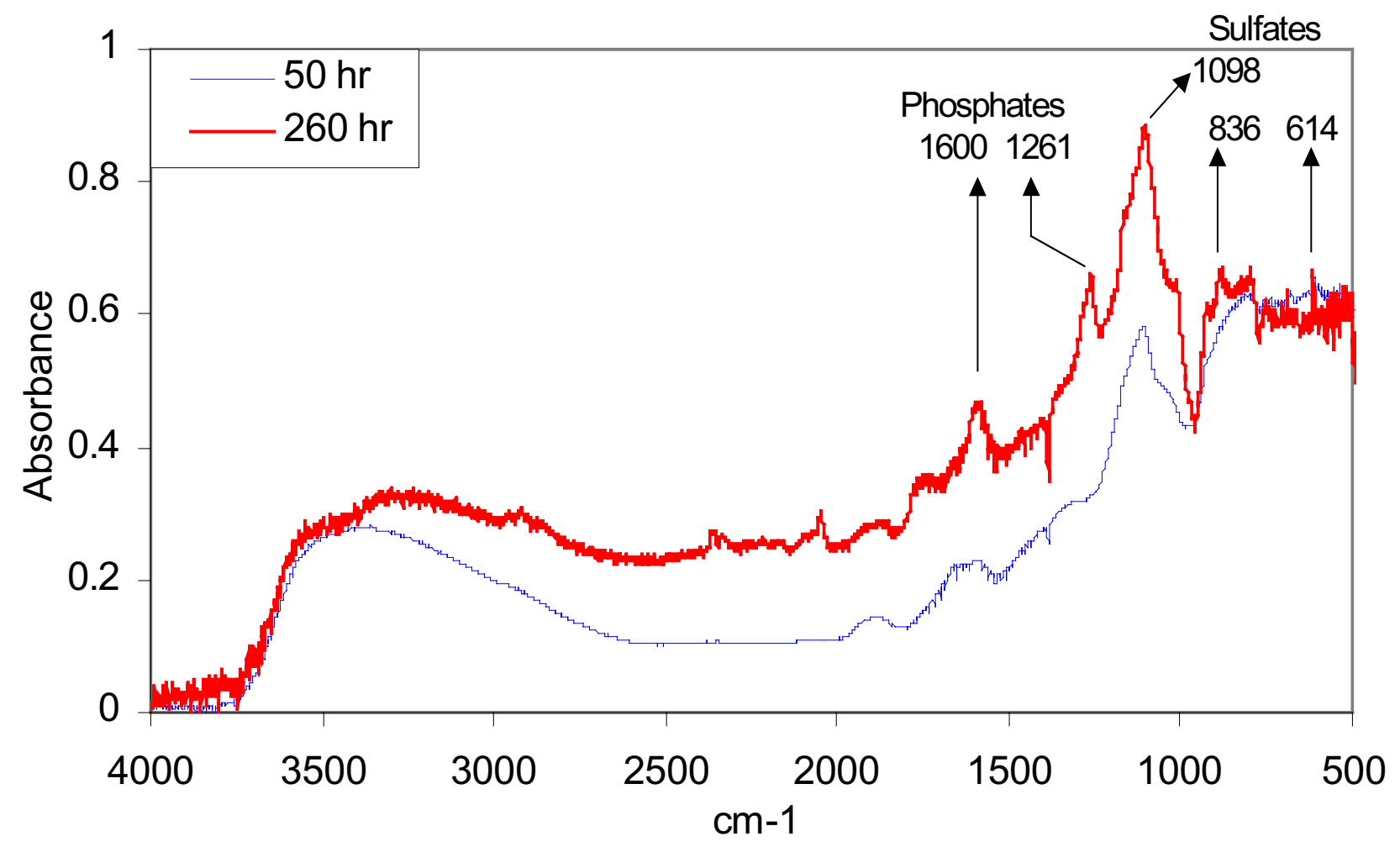

Figure 10 DRIFTS spectra of engine aged SOx trap as a function of time on stream 